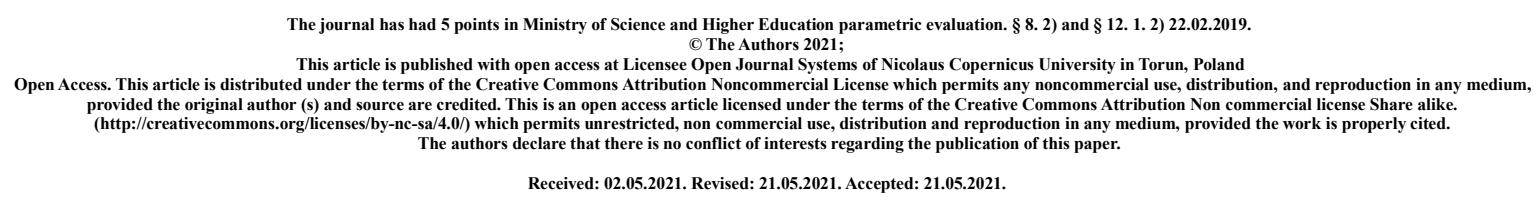

\title{
Acceptance of illness and quality of life in patients with type 2 diabetes
}

\author{
Sylwia Krzemińska ${ }^{1}$, Anna Kostka ${ }^{1}$
}

${ }^{1}$ Department of Clinical Nursing, Faculty of Health Science, Wroclaw Medical University, Wroclaw, Poland

Correspondence: Sylwia Krzemińska

Department of Clinical Nursing, Faculty of Health Sciences, Wroclaw Medical University, ul. K. Bartla 5, Wroclaw 51-618, Poland

Email sylwia.krzeminska@umed.wroc.pl

Sylwia Krzemińska ORCID 0000-0001-7695-0967

Anna Kostka ORCID 0000-0002-6111-0153

\begin{abstract}
Background: results of studies concerning the quality of life in chronic diseases and the predictors thereof are a source of valuable information making it possible to take the right actions, both educational, at every stage, and therapeutic. The assessment acceptance of illness and the quality of life enables the identification of patients' actual problems and objections as well as the recognition of their needs for the purpose of treatment optimization.

Objective: The aim of the study was to evaluate the acceptance of the disease and the quality of life of patients with type 2 diabetes.

Materials and methods: The study assessed disease acceptance and the quality of life in 194 people living with type 2 diabetes for over 10 years. The AIS (Acceptance of Illness) and WHOQoL -BREF questionnaires were used.
\end{abstract}

Results: Acceptance of illness in the study group was average 24.21 points ( $\mathrm{SD}=8.61$ ). 
Patients are not satisfied with the quality of their life and their own health. According to the assessment of patients, the quality of their life is the highest in the social domain (mean13.72 \pm 2.18 ), slightly worse in the environmental domain (mean $13.31 \pm 2.1$ ) and it is the worst in the mental (mean12.82 \pm 2.78 ) and physical (mean 12.02 \pm 3.24 ) domain. The AIS result significantly and positively correlated with each domain of life (all of them $p<0.05$ ), therefore, the higher the AIS result (better acceptance of illness).

Conclusion: Acceptance of illness is an independent predictor of the quality of life in terms of the perception of own health and the perception of the quality of life in general. It also affects all domains of life. The greater the acceptance of illness, the higher the quality of life in all domains.

Key words: acceptance of illness, quality of life, diabetes mellitus.

\section{Background}

Traditionally, the impact of a chronic disease would be measured by morbidity or mortality. For some time now, researchers have been also taking into account the health related quality of life (HRQoL), as an important and measurable result of medical interventions. By measuring the quality of life in patients with diabetes, we can predict the ability of a given person to handle the disease and maintain long-term health and well-being.[1]

Long-term treatment of type 2 diabetes usually requires patients to make dietary and lifestyle changes as well as follow therapeutic recommendations, which may have an impact on their quality of life (QoL). When QoL and/or satisfaction with treatment are affected by the therapeutic regimen, it may have a negative impact on the perception of the quality of life and cause an increase in the risk of complications.[2]

Such factors as patient's beliefs, attitude towards the disease and acceptance of the limitations imposed by it are important factors in the self-assessment of the quality of life in patients with type 2 diabetes. The assessment of the quality of life and the disease makes it possible to identify the actual problems and observations of patients as well as their needs.[3] It facilitates optimisation and individual adjustment of treatment as well as intensification of actions aimed at the elimination of risk factors.[4] Results of other studies concerning the quality of life of patients suffering from chronic diseases and its predictors constitute a source of valuable information, making it possible to take the right educational actions at each level: prevention, diagnosis and treatment of diabetes. Moreover, they enable better distribution of healthcare resources' [5]

Objective

The aim of the study was to evaluate the acceptance of illness and the quality of life of patients with type 2 diabetes.

\section{Material}

The study was conducted on a group of 210 patients with T2DM, patients under the care of a diabetes outpatient clinic in Wrocław.

In patients with $\mathrm{T} 2 \mathrm{DM}$, it consisted in a dietary regimen and administration of oral antidiabetic drugs as well as insulin, in cases where it was necessary. During the appointment at the clinic, HbAlc and glucose levels were measured in patients and pharmacological treatment was established. The patients also participated in educational activities concerning 
a proper diet, including the content of carbohydrates, protein and fats in food. Aerobic training was also recommended to the patients. Subsequently, the study was conducted with the use of the AIS and WHOQoL-BREF questionnaires. The questionnaire also included brief information on the personal data of each participant: age, sex, place of residence, education, marital status, professional activity, BMI (body mass index), comorbidities, the presence of diabetes complications and the taken medications. Only the results confirming the occurrence of diabetes complications and comorbidities that were validated by a specialist were taken into account.

The analysis included 194 persons who met all inclusion criteria: age above 40, duration of the disease exceeding 10 years, consent to participate in the study. Sixteen patients were not included in the study due to incomplete questionnaires.

Considering the fact that $6 \%$ of people in Poland are suffering from T2DM [6] and assuming that the maximum error is equal to $3 \%$ and the confidence level is $90 \%$, the minimum size of the sample is estimated to be 163 persons. Therefore, the size of the study sample was sufficient for the analysis.

The study was conducted in 2018 accordance with the principles for human research established by the Helsinki Declaration. Participation in the study was voluntary and each participant signed a consent form and was assured that the study would be kept anonymous. The purpose of the study and the way in which the questionnaires were to be completed was explained to the participants. The study protocol was approved by the independent Bioethics Committee of the Wroclaw Medical University (decision No. 622/2017).

\section{Method}

The study was conducted with the use of two standardised tools.

Acceptance of illness was measured with the use of Acceptance of Illness Scale (AIS), which was developed by Felton et al.[7] and adapted to the Polish conditions by Juczyński [8]. The scale consists of eight statements related to the limitations imposed by the disease, lack of independence stemming from it, the sense of being dependent of others, and reduced selfesteem. The participants were supposed indicate whether they agreed with a given statement using a 5-point scale, where 1 meant strongly agree; 2- agree; 3 - undecided; 4 - disagree; 5 strongly disagree. The total score of the scale ranged from 8 to 40; the higher score, the better acceptance of the disease. Cronbach's alpha for the Acceptance of Illness Scale (AIS) was 0.85 , similar to the value for the original scale (0.82). [9]

The general health-related quality of life was assessed with the use of the WHO Quality of Life Assessment (WHOQOL). It is a generic quality of life tool that was designed to be applicable to people living in different conditions, and cultures.[10,11] WHOQOL is based on a purely subjective evaluation and it assesses the perceived quality of life, which distinguishes it from many other tools. WHOQOL also views the quality of life as a multidimensional concept. It provides unweighted measures in four domains: physical health, psychological health, social relationships and environmental health. The physical domain consists of questions related to daily activities, treatment compliance, pain and discomfort, sleep and rest, energy and fatigue. The psychological domain includes questions regarding positive and negative feelings, self-esteem, body image and physical appearance, personal beliefs and attention. The social relationships domain assesses personal relationships, social support and sexual activity. The environmental domain explores physical security and safety, financial resources, health and social care and the availability thereof, opportunities for acquiring new information and skills and participation in opportunities for recreation and 
transport. It is based on a Likert-type scale and is scored from 1 to 5 , with higher scores indicating better quality of life [10] The reliability of the Polish version of WHOQoL-BREF is similar to the original version [12]. A very high $\alpha$-Cronbach factor was obtained, both in the evaluation of individual dimensions (results from 0.69 to 0.81 ) and the whole questionnaire (0.90) [13].

Statistical methods

Correlations between quantitative variables were analyzed using the Pearson correlation coefficient (when both were normally distributed) or Spearman (otherwise). The normality of the distribution of variables was tested using the Shapiro-Wilk test.

The strength of dependence was interpreted according to the following scheme:

$|\mathrm{r}| \geq 0.9$ - very strong relationship, by $0.7 \leq|\mathrm{r}|<0.9$ - strong relationship, by $0.5 \leq|\mathrm{r}|<0.7$ - moderately strong dependence, by $0.3 \leq|\mathrm{r}|<0.5$ - weak correlation, $|\mathrm{r}|<0.3$ - very weak (negligible) relationship [14]

The multivariate analysis of the independent influence of many variables on the quantitative variable was performed using the linear regression method. The results are presented as the values of the regression model parameters with a $95 \%$ confidence interval.

A significance level of 0.05 was adopted in the analysis. Thus, all p values below 0.05 were interpreted as showing significant relationships.

The analysis was performed in the R program, version 3.6.0. [15]

\section{RESULTS}

Characteristics of the studied group

The study group was composed of 194 people aged $61.64 \pm 7.89$, including $46.91 \%$ of women and $53.09 \%$ of men. The majority of participants lived in the country $(66.49 \%)$ and had secondary $(29.69 \%)$ and vocational $(29.38 \%)$ education. Most of the participants were in relationships $(66.49 \%)$. The majority of the participants were not professionally active, $32.99 \%$ were receiving a disability living allowance and retirement pension, while $5.15 \%$ were unemployed. Most of the participants also had hypertension (79.38\%) and were overweight or obese $(55.18 \%)$. The level of HbA1C was abnormal in most patients $(69,59 \%)$. Most of them also suffered from diabetes complications (Table 1).

Table 1. Characteristics of the study group

\begin{tabular}{|c|c|c|}
\hline & & Value \\
\hline \multirow{3}{*}{ Age [years] } & Mean \pm SD & $61,64 \pm 7,89$ \\
\hline & Median & 62 \\
\hline & Quartiles & $55-65,75$ \\
\hline \multirow[t]{2}{*}{ Gender } & Female & $91(46,91 \%)$ \\
\hline & Male & $103(53,09 \%)$ \\
\hline \multirow{3}{*}{ Place of residence } & Urban & $64(32,99 \%)$ \\
\hline & Rural & $129(66,49 \%)$ \\
\hline & Unknown & $1(0,52 \%)$ \\
\hline \multirow{2}{*}{ Education } & Primary & $31(15,98 \%)$ \\
\hline & Vocational & $57(29,38 \%)$ \\
\hline
\end{tabular}




\begin{tabular}{|c|c|c|}
\hline & Pre-university & $77(39,69 \%)$ \\
\hline & Higher & $29(14,95 \%)$ \\
\hline \multirow{3}{*}{ Marital status } & Not in relationship & $63(32,47 \%)$ \\
\hline & In relationship & $129(66,49 \%)$ \\
\hline & Unknown & $2(1,03 \%)$ \\
\hline \multirow{4}{*}{ Professional activity } & Currently working & $56(28,87 \%)$ \\
\hline & Not working & $10(5,15 \%)$ \\
\hline & Disability pension & $64(32,99 \%)$ \\
\hline & Retirement pension & $64(32,99 \%)$ \\
\hline \multirow{5}{*}{ Comorbidities * } & Coronary artery disease & $57(29,38 \%)$ \\
\hline & Hypertension & $154(79,38 \%)$ \\
\hline & Heart failure & $45(23,20 \%)$ \\
\hline & Renal failure & $35(18,04 \%)$ \\
\hline & Eye diseases (other than retinopathy) & $64(32,99 \%)$ \\
\hline \multirow{6}{*}{ BMI } & Underweight $(17-18,5)$ & $11(5,67 \%)$ \\
\hline & Normal weight $(18,5-25)$ & $76(39,18 \%)$ \\
\hline & Overweight (25-30) & $71(36,60 \%)$ \\
\hline & Obesity class 1 (30-35) & $30(15,46 \%)$ \\
\hline & Obesity class II (35-40) & $5(2,58 \%)$ \\
\hline & Obesity class III (>40) & $1(0,52 \%)$ \\
\hline \multirow{3}{*}{ Drugs * } & Oral antidiabetic & $75(38,66 \%)$ \\
\hline & Insulin & $135(69,59 \%)$ \\
\hline & Diet treatment & $124(63,92 \%)$ \\
\hline \multirow{4}{*}{ Complications of diabetes* } & Retinopathy & $71(36,60 \%)$ \\
\hline & Nephropathy & $29(14,95 \%)$ \\
\hline & Polyneuropathy & $49(25,26 \%)$ \\
\hline & Diabetic foot & $30(15,46 \%)$ \\
\hline \multirow[t]{2}{*}{$\mathrm{HbAlc}$} & Incorrect (>7\%) & $135(69,59 \%)$ \\
\hline & Correct $(\leq 7 \%)$ & $59(30,41 \%)$ \\
\hline
\end{tabular}

* The percentages do not add up to 100 as it was a multiple choice question.

\section{Acceptance of illness}

The mean AIS score was 24.21 points $(\mathrm{SD}=8.61)$, therefore, it was nearly equal to the "midpoint". Thus, it can be said that patients show moderate acceptance of diabetes (Table 2). 
Table 2. Acceptance of illness in the group

\begin{tabular}{cccccccc}
\hline \multicolumn{10}{c}{ AIS [points] } \\
\hline $\mathbf{N}$ & Mean & SD & Median & Min & Max & Q1 & Q3 \\
\hline $193 *$ & 24,21 & 8,61 & 24 & 8 & 40 & 17 & 32 \\
\hline$*$ one patient failed to complete the AIS & \multicolumn{10}{c}{. }
\end{tabular}

Most participants scored 21-24 points (19.07\%), i.e. moderate acceptance of illness, followed by $29-32$ points $(14.95 \%)$ and 33-36 points $(14.43 \%)$, i.e. high level acceptance of illness.

\section{WHOQoL BREF}

Perception of the quality of life

The greatest number of patients perceived their quality of life as neither good nor bad $(50.52 \%)$ and bad (25.77\%). The quality of life was considered to be bad by $5.15 \%$ of participants.

The mean rating of the quality of life in the study was 2.84 points ( $\mathrm{SD}=0.81$ ), which means that the participants rated their quality of life between bad and average (neither good nor bad) (Table 3).

Table 3. Quality of life perception

\begin{tabular}{ccc}
\hline Quality of life perception & $\mathbf{N}$ & $\mathbf{\%}$ \\
\hline Very bad & 10 & $5,15 \%$ \\
\hline Bad & 50 & $25,77 \%$ \\
\hline Neither good nor bad & 98 & $50,52 \%$ \\
\hline Good & 34 & $17,53 \%$ \\
\hline Very good & 2 & $1,03 \%$ \\
\hline
\end{tabular}

Perception of own health

Most participants rated their health as neither satisfactory nor unsatisfactory $(40.21 \%)$. Among the participants, $29.90 \%$ were not satisfied with their health and $5.15 \%$ were very dissatisfied with their health.

The mean rating of participants' own health was 2.87 points $(\mathrm{SD}=0.89)$, which means that it was between unsatisfactory and average (neither satisfactory nor unsatisfactory) (Table 4.). 
Table 4. Health perception

\begin{tabular}{ccc}
\hline Health perception & $\mathbf{N}$ & $\mathbf{\%}$ \\
\hline Very dissatisfied & 10 & $5,15 \%$ \\
\hline Dissatisfied & 58 & $29,90 \%$ \\
\hline Neither satisfied nor dissatisfied & 78 & $40,21 \%$ \\
\hline Satisfied & 44 & $22,68 \%$ \\
\hline Very satisfied & 4 & $2,06 \%$
\end{tabular}

Quality of life domains

According to the assessment of patients, the quality of their life is the highest in the social domain (mean13.72 \pm 2.18 ), it is slightly worse in the environmental domain (mean $13.31 \pm 2.1$ ) and it is the worst in the mental (mean12.82 \pm 2.78 ) and physical (mean 12.02 \pm 3.24 ) domain (Table 5).

Table 5. Results of domains WHOQoL BREF

\begin{tabular}{ccccccccc}
\hline WHOQoL BREF & N & Mean & SD & Median & Min & Max & Q1 & Q3 \\
\hline Physical domain & 194 & 12,02 & 3,24 & 12 & 5 & 18 & 10 & 15 \\
\hline Psychological domain & 194 & 12,82 & 2,78 & 13 & 5 & 18 & 11 & 15 \\
\hline Social domain & 194 & 13,72 & 2,18 & 13 & 8 & 19 & 12 & 15 \\
\hline Environment domain & 194 & 13,31 & 2,1 & 13 & 8 & 19 & 12 & 15 \\
\hline
\end{tabular}

AIS and WHOQoL-BREF correlation

The authors of the study decided to investigate whether there were correlations between acceptance of illness and the perception of the quality of life, own health and areas of the quality of life rated with the use of the WHOQoL-BREF questionnaire.

The AIS result significantly and positively correlated with each domain of life (all of them $\mathrm{p}<0.05$ ), therefore, the higher the AIS result (better acceptance of the disease), the higher the quality of life in all areas. With regard to the perception of the quality of life and own health the correlation is average, while in the domains of the quality of life the correlations are strong (Table 6.). 
Table 6. Correlation between tools

\begin{tabular}{ccccc}
\hline \multirow{2}{*}{ WHOQoL BREF } & \multicolumn{4}{c}{ Correlations with AIS } \\
\cline { 2 - 5 } & Correlation coefficient & $\mathbf{p} *$ & $\begin{array}{c}\text { Direction of } \\
\text { dependence }\end{array}$ & $\begin{array}{c}\text { The power of } \\
\text { dependence }\end{array}$ \\
\hline Quality of life perception & 0,638 & $\mathrm{p}<0,001 \mathrm{NP}$ & $\mathrm{positive}$ & average \\
\hline Health perception & 0,681 & $\mathrm{p}<0,001 \mathrm{NP}$ & $\mathrm{positive}$ & average \\
\hline Physical domain & 0,721 & $\mathrm{p}<0,001 \mathrm{NP}$ & positive & strong \\
\hline Psychological domain & 0,766 & $\mathrm{p}<0,001 \mathrm{NP}$ & positive & strong \\
\hline Social domain & 0,449 & $\mathrm{p}<0,001 \mathrm{NP}$ & positive & strong \\
\hline Environment domain & 0,734 & $\mathrm{p}<0,001 \mathrm{NP}$ & positive & strong \\
\hline \multirow{2}{*}{$\begin{array}{l}\mathrm{P}=\text { Normal distribution of both correlated variables, Pearson's correlation coefficient; NP }=\text { Lack of normality in the } \\
\text { distribution of at least one of the correlated variables, Spearman's correlation coefficient }\end{array}$}
\end{tabular}

Regression analyses

The applied linear regression model was used to verify whether AIS and the selected sociodemographic factors (age, gender, residence, education, marital status, professional activity) or clinical parameters (HbA1c levels, BMI, comorbidities, diabetes complications, treatment used) can affect QoL.

For the purpose of calculations, all levels of obesity were aggregated into one group.

The linear regression model showed that the independent predictors of the quality of life with regard to the perception of the quality of life are: AIS result Each additional point in the AIS questionnaire increases the quality of life in this domain by 0.062 points on average and retinopathy, it increases the quality of life in this domain by 0.285 points on average (Table 7 ).

The linear regression model showed that the independent predictor of the quality of life with regard to the perception of the quality of life is: AIS result Each additional point in the AIS questionnaire increases the quality of life in this domain by 0.07 points on average (Table 7).

The linear regression model showed that the independent predictor of the quality of life in the physical domain is $(p<0.05)$ : AIS result Each additional point in the AIS questionnaire increases the quality of life in this domain by 0.284 points on average ( Table 7 ).

The linear regression model showed that the independent predictors of the quality of life in the psychological domain are: AIS result Each additional point in the AIS questionnaire increases the quality of life in this domain by 0.239 points on average and retinopathy, it increases the quality of life in this domain by 0.952 points on average (Table 7 ).

The linear regression model showed that the independent predictor of the quality of life in the physical domain is $(p<0.05)$ : AIS result Each additional point in the AIS questionnaire increases the quality of life in this domain by 0.107 points on average (Table 7).

The linear regression model showed that the independent predictors of the quality of life in the physical domain are $(\mathrm{p}<0.05)$ : AIS result Each additional point in the AIS questionnaire increases the quality of life in this domain by 0.17 points on average and obesity, it decreases the quality of life in this domain by 0.76 points on average, compared to normal weight (Table7). 
Table 7. Linear regression results

\begin{tabular}{|c|c|c|c|c|c|c|c|c|c|c|c|c|c|}
\hline & \multirow{2}{*}{ Variable } & \multicolumn{2}{|c|}{$\begin{array}{l}\text { Quality of life } \\
\text { perception }\end{array}$} & \multicolumn{2}{|c|}{ Health perception } & \multicolumn{2}{|c|}{ Physical domain } & \multicolumn{2}{|c|}{ Psychological domain } & \multicolumn{2}{|c|}{ Social domain } & \multicolumn{2}{|c|}{ Environment domain } \\
\hline & & $\begin{array}{l}\text { Parameter } \\
\text { regression }\end{array}$ & $\mathrm{p}$ & $\begin{array}{l}\text { Parameter } \\
\text { regression }\end{array}$ & $\mathrm{p}$ & $\begin{array}{l}\text { Parameter } \\
\text { regression }\end{array}$ & $\mathrm{p}$ & $\begin{array}{l}\text { Parameter } \\
\text { regression }\end{array}$ & $\mathrm{p}$ & $\begin{array}{l}\text { Parameter } \\
\text { regression }\end{array}$ & $\mathrm{p}$ & $\begin{array}{l}\text { Parameter } \\
\text { regression }\end{array}$ & $\mathrm{p}$ \\
\hline AIS [points] & & 0,062 & $<0,001$ & 0,07 & $<0,001$ & 0,284 & $<0,001$ & 0,239 & $<0,001$ & 0,107 & $<0,001$ & 0,17 & $<0,001$ \\
\hline Age [years] & & 0,004 & 0,736 & 0,015 & 0,193 & $-0,028$ & 0,464 & 0,039 & 0,212 & 0,006 & 0,856 & 0,011 & 0,665 \\
\hline \multirow{2}{*}{ Gender } & Female & ref. & & ref. & & ref. & & ref. & & ref. & & ref. & \\
\hline & Male & 0,162 & 0,186 & 0,076 & 0,578 & 0,4 & 0,376 & 0,325 & 0,368 & 0,146 & 0,722 & $-0,214$ & 0,45 \\
\hline \multirow{2}{*}{ Place of residence } & Urban & ref. & & ref. & & ref. & & ref. & & ref. & & ref. & \\
\hline & Rural & $-0,123$ & 0,321 & 0 & 0,999 & 0,528 & 0,25 & $-0,088$ & 0,81 & 0,077 & 0,853 & 0,056 & 0,847 \\
\hline \multirow{4}{*}{ Education } & Primary & ref. & & ref. & & ref. & & ref. & & ref. & & ref. & \\
\hline & Vocational & 0,041 & 0,798 & $-0,123$ & 0,493 & $-0,115$ & 0,847 & 0,069 & 0,885 & 0,262 & 0,629 & 0,106 & 0,777 \\
\hline & Pre-university & 0,1 & 0,628 & 0,172 & 0,456 & $-0,302$ & 0,693 & 0,508 & 0,406 & 0,003 & 0,996 & $-0,107$ & 0,823 \\
\hline & Higher & $-0,036$ & 0,885 & 0,087 & 0,756 & $-1,163$ & 0,209 & 0,421 & 0,569 & 0,15 & 0,858 & 0,592 & 0,307 \\
\hline \multirow{2}{*}{ Marital status } & Not in relationship & ref. & & ref. & & ref. & & ref. & & ref. & & ref. & \\
\hline & In relationship & $-0,074$ & 0,603 & $-0,014$ & 0,931 & $-0,538$ & 0,309 & $-0,31$ & 0,463 & $-0,034$ & 0,943 & $-0,182$ & 0,583 \\
\hline \multirow{4}{*}{$\begin{array}{l}\text { Professional } \\
\text { activity }\end{array}$} & Currently working & ref. & & ref. & & ref. & & ref. & & ref. & & ref. & \\
\hline & Not working & 0,097 & 0,712 & 0,337 & 0,254 & 0,251 & 0,797 & 0,778 & 0,319 & 0,192 & 0,829 & 0,435 & 0,478 \\
\hline & Disability pension & $-0,142$ & 0,345 & $-0,092$ & 0,583 & 0,269 & 0,629 & $-0,519$ & 0,243 & 0,063 & 0,901 & $-0,178$ & 0,609 \\
\hline & Retirement pension & $-0,064$ & 0,725 & $-0,122$ & 0,548 & 0,946 & 0,16 & $-0,719$ & 0,18 & 0,764 & 0,211 & $-0,283$ & 0,501 \\
\hline \multirow{2}{*}{$\begin{array}{l}\text { Coronary artery } \\
\text { disease }\end{array}$} & No & ref. & & ref. & & ref. & & ref. & & ref. & & ref. & \\
\hline & Yes & 0,099 & 0,465 & 0,194 & 0,202 & 0,043 & 0,931 & 0,756 & 0,061 & $-0,249$ & 0,586 & 0,441 & 0,163 \\
\hline \multirow{2}{*}{ Hypertension } & No & ref. & & ref. & & ref. & & ref. & & ref. & & ref. & \\
\hline & Yes & $-0,196$ & 0,175 & $-0,122$ & 0,45 & $-0,617$ & 0,249 & $-0,748$ & 0,081 & 0,26 & 0,592 & 0,011 & 0,973 \\
\hline \multirow{2}{*}{ Heart failure } & No & ref. & & ref. & & ref. & & ref. & & ref. & & ref. & \\
\hline & Yes & 0,034 & 0,817 & $-0,13$ & 0,425 & $-0,313$ & 0,56 & $-0,316$ & 0,463 & 0,415 & 0,397 & $-0,248$ & 0,463 \\
\hline \multirow{2}{*}{ Renal failure } & No & ref. & & ref. & & ref. & & ref. & & ref. & & ref. & \\
\hline & Yes & $-0,009$ & 0,97 & $-0,03$ & 0,911 & 0,552 & 0,536 & 0,108 & 0,88 & $-0,573$ & 0,48 & 0,354 & 0,527 \\
\hline \multirow{2}{*}{ Eye disease } & No & ref. & & ref. & & ref. & & ref. & & ref. & & ref. & \\
\hline & Yes & $-0,112$ & 0,343 & $-0,041$ & 0,757 & $-0,305$ & 0,486 & 0,058 & 0,867 & 0,164 & 0,679 & 0,172 & 0,532 \\
\hline \multirow{4}{*}{ BMI } & $\begin{array}{c}\text { Normal weight } \\
(18,5-25)\end{array}$ & ref. & & ref. & & ref. & & ref. & & ref. & & ref. & \\
\hline & Underweight $(<18,5)$ & 0,341 & 0,182 & 0,14 & 0,622 & 1,232 & 0,193 & 0,114 & 0,88 & 0,333 & 0,698 & $-0,272$ & 0,646 \\
\hline & Overweight (25-30) & 0,023 & 0,841 & $-0,043$ & 0,735 & 0,084 & 0,842 & $-0,446$ & 0,188 & $-0,207$ & 0,59 & $-0,088$ & 0,739 \\
\hline & Obesity $(>30)$ & 0,087 & 0,551 & $-0,127$ & 0,438 & 0,661 & 0,222 & $-0,449$ & 0,299 & $-0,387$ & 0,431 & $-0,76$ & 0,026 \\
\hline \multirow{2}{*}{ Oral antidiabetic } & No & ref. & & ref. & & ref. & & ref. & & ref. & & ref. & \\
\hline & Yes & $-0,108$ & 0,551 & $-0,218$ & 0,282 & 0,06 & 0,928 & 0,298 & 0,578 & 0,561 & 0,357 & 0,228 & 0,587 \\
\hline Insulin & No & ref. & & ref. & & ref. & & ref. & & ref. & & ref. & \\
\hline
\end{tabular}




\begin{tabular}{|c|c|c|c|c|c|c|c|c|c|c|c|c|c|}
\hline & Yes & $-0,356$ & 0,065 & $-0,195$ & 0,363 & $-0,369$ & 0,603 & $-0,079$ & 0,889 & 0,741 & 0,251 & 0,762 & 0,088 \\
\hline \multirow{2}{*}{ Diet treatment } & No & ref. & & ref. & & ref. & & ref. & & ref. & & ref. & \\
\hline & Yes & $-0,121$ & 0,336 & $-0,058$ & 0,677 & $-0,245$ & 0,598 & 0,194 & 0,601 & 0,185 & 0,661 & 0,235 & 0,421 \\
\hline \multirow{2}{*}{$\begin{array}{l}\text { Complications of } \\
\text { diabetes } \\
\text { Retinopathy }\end{array}$} & No & ref. & & ref. & & ref. & & ref. & & ref. & & ref. & \\
\hline & Yes & 0,285 & 0,019 & 0,017 & 0,898 & 0,203 & 0,649 & 0,952 & 0,008 & $-0,287$ & 0,479 & 0,301 & 0,282 \\
\hline \multirow{2}{*}{$\begin{array}{l}\text { Complications of } \\
\text { diabetes } \\
\text { Nephropathy }\end{array}$} & No & ref. & & ref. & & ref. & & ref. & & ref. & & ref. & \\
\hline & Yes & $-0,131$ & 0,607 & $-0,205$ & 0,472 & $-0,824$ & 0,382 & $-0,68$ & 0,367 & 0,439 & 0,608 & $-0,682$ & 0,249 \\
\hline \multirow{2}{*}{$\begin{array}{l}\text { Complications of } \\
\text { diabetes } \\
\text { Neuropathy }\end{array}$} & No & ref. & & ref. & & ref. & & ref. & & ref. & & ref. & \\
\hline & Yes & $-0,219$ & 0,228 & 0,118 & 0,56 & $-0,314$ & 0,641 & 0,279 & 0,602 & $-0,018$ & 0,977 & 0,034 & 0,936 \\
\hline \multirow{2}{*}{$\begin{array}{c}\text { Complications of } \\
\text { diabetes } \\
\text { Diabetic foot }\end{array}$} & No & ref. & & ref. & & ref. & & ref. & & ref. & & ref. & \\
\hline & Yes & $-0,067$ & 0,708 & $-0,067$ & 0,736 & 0,14 & 0,832 & $-0,429$ & 0,418 & $-0,648$ & 0,283 & $-0,645$ & 0,122 \\
\hline \multirow{2}{*}{$\mathrm{HbAlc}$} & Incorrect $(>7 \%)$ & ref. & & ref. & & ref. & & ref. & & ref. & & ref. & \\
\hline & Correct $(\leq 7 \%)$ & $-0,056$ & 0,633 & $-0,085$ & 0,513 & 0,092 & 0,832 & $-0,523$ & 0,13 & $-0,308$ & 0,432 & $-0,023$ & 0,932 \\
\hline
\end{tabular}

\section{$\mathrm{R}^{2}$ coefficients}

The $\mathrm{R}^{2}$ coefficient for the above models ranged from $24.02 \%$ (for the social domain of life), through $50.6 \%$ (for the perception of own health), $51.43 \%$ (for the perception of the quality of life), $58.06 \%$ (for the physical domain), $60.69 \%$ (for the environmental domain) to $63.88 \%$ (for the psychological domain), which means that this many variations of results were explained by the variables included in the model. The remaining $36.12-75.98 \%$ depend on the variables not included in the model and random factors.

\section{Discussion}

Acceptance of illness is an important factor conditioning the quality of life in patients with chronic diseases. Undoubtedly, diabetes is one of them. A patient who accepts and understands the condition of their own health is able to better control the disease and take better care of himself or herself. Their quality of their life thus changes for the better. There are many studies concerning the level of disease acceptance in various chronic diseases, such as cardiovascular diseases [16], respiratory diseases [17] and diseases of the musculoskeletal system as well as diabetes mellitus [18], where the results obtained among patients with diabetes were similar to the results obtained in the authors' own study [19]. The level of disease acceptance among the participants of the authors' own study is average. Similar results were obtained by Juczyński[8], while the results obtained by Felton [9] and Starczewska et al. [20] indicated a much higher level of disease acceptance among diabetes patients.

The authors' own studies show that disease acceptance has a great impact on the quality of life in all areas. The greater the acceptance of the disease, the better the perception of one's own health.

In the authors' own study, the AIS result significantly and positively correlates with each domain of life, therefore, the higher the AIS result (better acceptance of the disease), the higher the quality of life in all domains. It is of great practical importance in the case of diabetes patients, which is also discussed in the paper by Kugbey et al. According to these 
authors, the level of self-care and the level of adherence to recommendations depends on the perception of the disease as well as own health.[21]

Diabetes is a chronic and irreversible disease which persists throughout a person's life. It indirectly concerns all people of all ages and their families and constitutes a heavy financial burden, affects self-care and shortens life expectancy due to the chronic damage that it causes. Therefore, the broadly understood quality of life in patients with diabetes may vary. The authors' own studies show that the majority of people with diabetes consider their quality of life to be neither good nor bad. Comparing the quality of life of diabetes patients with that of healthy individuals, Tavakkoli et al. [22] obtained a much lower result in people diagnosed with diabetes. On the basis of the obtained results, the authors concluded that the quality of life among diabetes patients was moderate, and such result was affected by demographic factors. In addition, the results obtained in the group of patients were the highest in the environmental domain. The rating of the psychological domain, on the other hand, was the worst.

The authors' own study also showed that the perception of the quality of life in the psychological and physical domain was the poorest among diabetes patients. Similar results were obtained by Ahari et al.[23] The authors state that the psychological and physical domains of life are most affected in people with diabetes. Studies conducted by Qhsemi-Pour et al.[24] show that over $70 \%$ of patients with diabetes had much lower quality of life in terms of their physical and mental well-being. In a study conducted by Kolawole et al [25] it can be observed that patients with diabetes give the highest rating to the environmental domain.

In a study conducted by Kurpas D. et al.[26] all survey participants showed greatest satisfaction with life in the social domain, followed by the physical and environmental domains. It also was the lowest in the psychological domain. The psychological domain was also the source of greatest dissatisfaction in the studies conducted by Motyka H. et al.[27] According to Polish authors, the averages for particular scales of the quality of life are within average results and are relatively similar to one another, except for the quality of life in the social domain, which was rated the highest by the respondents. Thus, the quality of life in the domain of social relationships turned out to be the highest in comparison with other domains of the quality of life, both in type 1 and type 2 diabetes. Patients from the study group also rated the quality of life in the social domain the highest, while the quality of life in the environmental domain was rated slightly worse.

According to many authors, demographic aspects have an impact on the quality of life in diabetes patients. In their studies, Tavvakoli L. et al. observed a significant impact of the sex and economic status on the physical domain.[28] Sanjay Pandey et al. draw attention to the impact of the dietary pattern on both the social and the environmental domain. According to these authors, BMI has a significant impact on the psychological domain, similarly to hypertension.[29]

In this study, the authors did not obtain information regarding the impact of body mass on the psychological domain, but on the environmental domain. Compared to normal weight, obesity decreases the quality of life in this domain.

Concurrent diseases also have an impact on the quality of life of patients with diabetes, most often decreasing it. Interestingly, as the authors' own studies show, retinopathy improves the quality of life in, among other things, the psychological domain. Conclusions reached by Sharma et al. in their meta-analysis of the problem were completely different.[30] In the reports of other researchers, the presence of diabetes complications in most cases decreases 
the quality of life in each domain, having the greatest impact on the physical and psychological domain thereof.[31]

\section{Conclusions}

In summary, patients with diabetes participating in this study show average acceptance of their disease and are also not satisfied with their quality of life and own health. They give the highest rating to their quality of life in the social domain, and slightly lower in the environmental domain. They consider their quality of life to be the poorest in the psychological and physical domain.

Acceptance of illness is an independent predictor of the quality of life in terms of the perception of own health and the perception of the quality of life in general. It also affects all domains of life. The greater the acceptance of illness, the higher the quality of life in all domains.

Abbreviations

AIS Acceptance of Illness Scale

BMI - Body Mass Impact

DM - Diabetes Mellitus

HbA1C- glycated hemoglobin

HRQoL -Health Related Quality f Life

QoL -Quality of Life

T2DM- Diabetes Mellitus Type 2

WHOQoL-BREF - WHO Quality of Life Assessment

\section{Declarations}

\section{Ethics approval and consent to participate}

The study was conducted with the principles for human research established by the Helsinki Declaration. Participation in the study was voluntary and each participant signed a consent form and was assured that the study would be kept anonymous. The purpose of the study and the way in which the questionnaires were to be completed was explained to the participants. The study protocol was approved by the independent Bioethics Committee of the Wroclaw Medical University (decision No. 622/2017).

Availability of data and materials

The datasets used and/or analysed during the current study are available from the corresponding author on reasonable request.

\section{Consent for publication}

Not applicable

\section{Competing interests}

The author declare that they have no conflict of interest. 


\section{Funding}

Research supported by the Wroclaw Medical University SUB.E020.21.002. (will finance the publication)

\section{Authors' contributions}

SK made a significant contribution to the concept and design of the work; data analysis and interpretation; prepared a sketch of the work and made a substantive correction.

AK concept and design of the work; data analysis and interpretation; prepared a sketch of the work.

\section{References}

1. Pichon-Riviere, A., Irazola, V., Beratarrechea, A., Alcaraz, A., Carrara, C. (2015). Quality of Life in Type 2 Diabetes Mellitus Patients Requiring Insulin Treatment in Buenos Aires, Argentina: A Cross-Sectional Study. International Journal of Health Policy and Management, 4(7), 475-480. doi: 10.15171/ijhpm.2015.80

2. Krzemińska S, Bąk E, Šáteková L, Polanská A, Hašová K, Laurinc M. Comparison of Diabetes-Dependent Quality of Life (ADDQoL) in Patients with T2DM in Poland, The Czech Republic, and Slovakia. Diabetes Metab Syndr Obes. 2020;13:3773-3786 https://doi.org/10.2147/DMSO.S273339

3. Zygmuntowicz M., Olszanecka-Glinianowicz M., Chudek J. Quality of life with arterial hypertension. Endocrinology, Obesity and Metabolic Disorders 2011; 7: 179-185.

4. Jankowska-Polańska B. Ilko A. Wleklik M.: Arterial Influence the acceptance of the disease on quality of life of patients with hypertension. Hypertension 2014, 18, 3: 143 - 150.

5. Pokorna-Kałwak D., Muszyńska A., Mastalerz-Migas A . Elderly hypertensive patient the impact of the disease and treatment on the patient's well-being. Psychogeriatria Polska 2008; 5: 37-46.

6. Statistical Report: Diabetes statistics in Poland and in the world. [w języku polskim] http://cukrzycapolska.pl/cukrzyca/statystyki. Dostęp: 08.12.2020

7. Felton BJ, Revenson TA, Hinrichsen GA. AIS-acceptance of illness scale. W: Juczyński

Z. Measurement tools in Promotion and Health Psychology. Warszawa: Laboratory of Psychological Tests of Polish Psychological Association, 2001:158-67.

8. Juczyński Z. Measurement tools in the promotion and psychooncology of health. Warszawa, Polska: Pracownia Testów Psychologicznych, 2009.

9. Felton BJ, Revenson TA. Coping with chronic illness: a study of illness controllability and the influence of coping strategies on psychological adjustment. J Consult Clin Psychol. 1984 Jun;52(3):343-53. doi: 10.1037//0022-006x.52.3.343. PMID: 6747054.

10. WHOQOL Group.The World Health Organization WHOQOL-BREF Quality of Life Assessment.Psychol. Med. 1998; 28: 551- 558.

11. Eser S, Saatli G, Eser E, Baydur H, Fidaner C. Yaşlilar Için Dünya Sağlik Orgütü Yaşam Kalitesi Modülü WHOQOL-OLD: Türkiye Alan Calişmasi Türkçe Sürüm [The reliability and validity of the Turkish Version of the World Health Organization Quality of Life Instrument- 
Older Adults Module (WHOQOL-Old)]. Turk Psikiyatri Derg. 2010 Spring;21(1):37-48. Turkish. PMID: 20204903.

12. Wołowicka L, Jaracz K. Polisch version WHOQOL -WHOQOL-100 i WHOQOLBref. W: Wołowicka L. (red.) Quality of life in medicalsciences. Poznań; Dział Wydawnictw Uczelnianych Akademii Medycznej, 2001.

13. Jaracz K, Kalfoss M, GórnaK, Baczyk G. Quality of life in Polish respondents: psychometric properties of the Polish WHOQOL-Bref. Scand J Caring Sci. 2006;20(3):251260.

14. Hinkle DE, Wiersma W, Jurs SG. Applied Statistics for the Behavioral Sciences. 5th ed. Boston: Houghton Mifflin; 2003.

15. R Core Team (2019). R: A language and environment for statistical computing. R Foundation for Statistical Computing, Vienna, Austria. URL https://www.R-project.org/.

16. Obiegło M, Uchmanowicz I, Wleklik M, Jankowska-Polańska B, Kuśmierz M. The effect of acceptance of illness on the quality of life in patients with chronic heart failure. Eur $\mathrm{J}$ Cardiovasc Nurs. 2016 Jun;15(4):241-7. doi: 10.1177/1474515114564929. Epub 2015 Jan 8. PM ID: 25573903.

17. Donata Kurpas, Bozena Mroczek, Helena Knap-Czechowska, Dorota Bielska, Aneta Nitsch-Osuch, Krzysztof Kassolik, Waldemar Andrzejewski, Anna Gryko, Andrzej Steciwko, Quality of life and acceptance of illness among patients with chronic respiratory diseases, Respiratory Physiology \& Neurobiology, 187, 1, 2013, 114-117, https://doi.org/10.1016/j.resp.2013.02.009.

18. Akvardar, Y, Akdede, B.B., Özerdem A., Eser, E., Topkaya, Ş. Alptekin K. (2006), Assessment of quality of life with the WHOQOL-BREF in a group of Turkish psychiatric patients compared with diabetic and healthy subjects. Psychiatry and Clinical Neurosciences, 60: 693-699. https://doi.org/10.1111/j.1440-1819.2006.01584.x

19. Janowski K, Kurpas D, Kusz J, Mroczek B, Jedynak T (2013) Health-Related Behavior, Profile of Health Locus of Control and Acceptance of Illness in Patients Suffering from

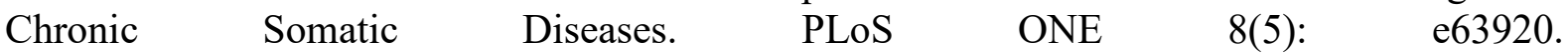
https://doi.org/10.1371/journal.pone.0063920

20. Starczewska M, Kujawska R, Stanisławska M, Rybicka A, Grochans E. The analysis of health behaviours and illness acceptance in patients with diabetes. Family Medicine \& Primary Care Review. 2018;20(4):352-355. doi:10.5114/fmpcr.2018.79347.

21. Kugbey N., Asante KO., Adulai K.; Illness perception, diabetes knowledge and self-care practices among type-2 diabetes patients: a cross-sectional study; BMC Res Notes. 2017; 10: 381.

22. Tavakkoli L., Dehghan A; Compare the Quality of Life in Type 2 Diabetic Patients with Healthy Individuals (Application of WHOQOL-BREF); Zahedan J Res Med Sci. In Press(In Press):e5882; Published online 2017 February 13

23. Ahari SS, Arshi S, Iranparvar M, Amani F, Siahpush H. The effects of type II diabetes on quality of life. Journal of Ardebil University of Medical Sciences. 2008;12(4):394-402.

24. Qhsemi-Pour M, Ghasemi V, Zamani A. Quality of life in diabetic patients referred to Shohada hospital in Khorramabad in 2008. J Lorestan Univ Med Sci. 2014;11(3):125-33.

25. Kolawole BA, Mosaku SK, Ikem RT. A comparison of two measures of quality of life of Nigerian clinic patients with type 2 diabetes mellitus. Afr Health Sci. 2009;9(3):161-6. 
26. Kurpas D., Czech T., Mroczek B.l Quality of life in patients with diabetes - what do complications mean?; Family Medicine \& Primary Care Review 2012, 14, 2: 177-181

27. Motyka H. Stanisz-Wallis K.; Selected quality of life determinants in diabetes; Nowa Medycyna 3/2013, s. 115-123

28. Tavakkoli L, Dehghan A. Compare the Quality of Life in Type 2 Diabetic Patients with Healthy Individuals (Application of WHOQOL-BREF), Zahedan J Res Med Sci. 2017 ; 19(2): e5882. doi: 10.5812/zjrms.5882.

29. Pandey, S., Kumar, P., Singh, C., Ranjan, A., Bhar, D., \& Agrawal, N. (2020). Quality of life using WHOQOL-BREF of Patients with Type 2 Diabetes mellitus attending a Primary Health Centre of Patna, India . Indian Journal of Preventive \& Social Medicine, 51(3), 151157. Retrieved from http://ijpsm.co.in/index.php/ijpsm/article/view/281

30. Sharma S, Oliver-Fernandez A, Liu W, Buchholz P, Walt J. The impact of diabetic retinopathy on health-related quality of life. Curr Opin Ophthalmol. 2005 Jun;16(3):155-9. doi: 10.1097/01.icu.0000161227.21797.3d. PMID: 15870571.

31. Kurpas D., Czech T.,Mroczek D.: Quality of life in patients with diabetes - what do complications mean? Family Medicine \& Primary Care Review 2012, 14, 2: 177-18 